\title{
Música y estados de conciencia en fiestas rituales de Chile central. Inmenso puente al universo*
}

\section{Claudio Mercado}

\begin{abstract}
"usté ya ha estado en hartas fiestas pue, y no va a poder dejar de venir porque esto es así, no lo va a poder cortar así no más, va a tener que seguir viniendo"

(tamborero del baile chino de Ventana)

tocar, tocar con esa emoción que cubre los labios y me hace girar en 500 grados hacia todas direcciones al mismo tiempo, una hormiga más en esta inmensa noche, un sonido más de este inmenso sonido que sale de los cerros, de los vendedores, de los niños, de los bombos, de las flautas, de los pasos, del sudor que teje una sombra hacia la noche y la dobla en mis ojos; tocar, sólo tocar

(nota de campo).
\end{abstract}

\section{INTRODUCCIÓN}

Este escrito sobre los "bailes chinos" - cofradías de danzantes de comunidades de pescadores y campesinos de Chile central que expresan su fe a través de la música y la danza en fiestas ceremoniales - relaciona la estética musical

*Este trabajo ha sido posible gracias al proyecto FONDECYT N 92-0351 "Estructuras arcaicas en la devoción popular en la IV y $\mathrm{V}$ región: estudio de la música instrumental de los bailes de turbantes, danzantes y chinos". 
y el ritual desarrollado por estos grupos, con la presencia de ciertas condiciones capaces de producir estados especiales de conciencia. ${ }^{1}$

Algunas características del ritual en que es ejecutada esta música incluye la necesidad de realizar un tremendo esfuerzo físico para lograr el sonido deseado y para realizar al mismo tiempo una danza de tipo acrobático durante varias horas seguidas, lo que implica un fuerte estado de hiperventilación. saturación del espacio sonoro debido a la cualidad y volumen de la música, palabras muy sentidas que canta el alférez y que los chinos repiten a coro, significación del ritual (presencia de la imagen adorada, mandas, etc.).

Los "chinos" del interior son en su mayoría campesinos que viven en pueblos como Olmué, Granizo y Pachacamita o en pequeñas comunidades como El Tebal o Palmas de Alvarado. Su subsistencia se basa en la agricultura a pequeña escala de tomates y repollos y en el trabajo del carbón.

Por otro lado, los "chinos" de la zona costera son en su mayoría pescadores artesanales y su subsistencia está de algún modo relacionada a los productos marinos; viven en pequeñas caletas como Maitencillo, Horcón y Zapallar o en ciudades costeras como Quintero y Concón.

El sentimiento religioso entre campesinos y pescadores es profundo; ellos dependen directamente de la naturaleza para su supervivencia y de esta manera se establece una relación de favores y gracias con la divinidad; a la divinididad se le baila, se le toca y se le canta para obtener ciertas necesidades fundamentales; salud, lluvias y una buena cosecha en el interior; protección y abundante pesca en el litoral.

El sistema religioso en que se insertan es el católico, respetan a los curas como los representantes de la iglesia y las fiestas se realizan en honor a los santos católicos, a la Virgen, y en otros días festivos del calendario ritual católico como Corpus Christi, Semana Santa, Ascensión de la Virgen y Navidad.

El ritual de bailes chinos podría insertarse dentro de un marco general de rituales populares americanos, en los que confluyen aspectos propiamente locales (el tipo de música instrumental, los instrumentos musicales, la relación entre la música y estados especiales de conciencia) y otros españoles (el canto del alférez, la institución católica y su corpus de imágenes sagradas). Aunque las comunidades que lo practican no son indígenas (no quedan indígenas en el área, que es la más occidentalizada del país) sino campesinos y pescadores que podrían ser catalogados como mestizos, parecieran conservar un sustrato indígena que ha logrado mantenerse pese a la fuerza de la cultura dominante.

\footnotetext{
'Este trabajo es el resultado de dos años de estudio en los que hemos asistido a 21 fiestas rituales en la zona central de Chile, y a numerosos ensayos de bailes, además de una gran cantidad de días conversando con sus cultores; chinos antiguos, constructores de flauta, alféreces y aprendices. La Investigación ha sido realizada en conjunto con José Pérez de Arce y Agustín Ruiz.

${ }^{2}$ Chino es una palabra quechua que significa "servidor", "sirviente", ellos sirven a la virgen y a los santos. (Lenz., S.F., pp. 294-295).
} 
Los elementos que sostienen esta suposición serán presentados en páginas posteriores.

Luego de un período de un año de asistir a fiestas y a terrenos, fui invitado a integrarme al baile de Cai Cai como flautero. La invitación fue hecha por Armando Reyes, uno de los principales promotores y sostenedores del baile, después de escucharme tocar las flautas y reconocer el sonido como un "buen sonido". A partir del término de la primera fiesta en que bailé y que fui reconocido como un "buen chino", la relación con los chinos cambió sustancialmente, abriéndose una puerta para acercarme a lo que motiva este estudio; lo que le ocurre a quien participa del ritual tocando y danzando durante horas seguidas.

He incluido en este trabajo lo que he llamado "notas de campo", escritos que intentan describir lo que he sentido mientras "chineo" en diversas fiestas, que intentan de alguna manera y con una escritura totalmente personal y alejada del lenguaje científico formal, acercarme y acercar al lector a esa emoción tan profunda que me traspasa mientras chineo, y que estoy seguro, de alguna manera ayudará a comprender lo que se intenta explicar en términos más "objetivos" o científicos.

$\mathrm{Y}$ aunque no soy un verdadero chino, pues mi acervo cultural difiere bastante de el de ellos, me parece absolutamente válido tratar de dar la mayor información posible, desde diversas perspectivas, para que el lector pueda formarse una idea más completa de lo que ocurre mientras el chino toca y danza durante horas seguidas.

El texto es entonces abordado desde tres puntos de vista: el del etnógrafo que ha observado durante dos años las fiestas, participando desde adentro y desde afuera, mirando, escuchando, conversando, aprendiendo y tomando una enorme cantidad de datos empíricos que relaciona y desarma y vuelve a relacionar para entender algo y armar el rompecabezas al que está enfrentado; el de los informantes, que hablan con su propio lenguaje y explican desde su punto de vista — evidentemente el punto de vista más autorizado de los treslo que ocurre mientras se chinea en una fiesta, y por último el del aprendiz que entra directamente en el ritual e intenta describir subjetivamente lo que le ocurre en sus zonas más internas mientras toca su flauta en una fiesta de chinos.

Y esta última perspectiva es muy importante porque no entiendo la etnografía como una simple recolección y descripción de datos, un tomar al "informante" como una fuente rebosante de información y quebrarse la cabeza inventando mejores técnicas para obtener el máximo de provecho, mi sentido de la etnografía es otro, es intentar de algún modo establecer un puente entre dos personas para hacer un intercambio de información, valores, experiencias; un aprendizaje de vida, un medio por el cual acceder a un conocimiento que ha sido totalmente extirpado de nuestra tradición cultural y que es mantenida por esas "otras culturas". Cuando digo puente me refiero a algo que fluye 
dialécticamente porque así como yo obtengo una información y una experiencia que en términos personales considero que ha influido en mi vida de manera muy fuerte, él - "el otro"— también obtiene información de mí que es válida y que le sirve para entender un poco más a "esos otros" que somos nosotros.

\section{CARACTERISTíCAS GENERALES DEL RITUAL DE LOS BAILES ChINOS}

Un ritual de bailes de chinos es una fiesta que organiza una determinada comunidad, pueblo o caleta para celebrar a un santo, a la Virgen, al Niño Dios o alguna fecha importante del calendario católico. El pueblo que celebrará la fiesta invita a grupos de bailes de otros pueblos y todos se juntan el día determinado a tocar y danzar en honor de la imagen venerada.

La fiesta es un encuentro intercomunitario, los bailes invitados asisten con sus familiares y amigos, es un encuentro al que acude gente de diversos lugares, es una fiesta en que lo sagrado y lo profano se relacionan de tal manera que conforman un espacio y tiempo únicos; es una día para pasarlo bien, para reír y ver a los amigos, a los conocidos, a los familiares de otros pueblos, un día para comprar y comer. Muchas veces se instalan ferias de comerciantes ambulantes y de entretenciones con ruedas y caballitos, todo esto junto al sentimiento sagrado, a la devoción expresada en la danza, en la música, en la procesión y en el paseo a la imagen sagrada.

Las fiestas suelen comenzar alrededor de las nueve de la mañana y prolongarse hasta el anochecer. Durante todo este tiempo el espacio sonoro se encuentra saturado por una gran batahola compuesta por el sonido de las flautas de chino, los bombos y los tambores de todos los bailes que tocan simultáneamente, los gritos de los comerciantes, de los niños que juegan, de los altoparlantes de los curas, etc.

El rito comienza con los saludos entre el baile dueño de casa y los bailes invitados según su orden de llegada.

En el saludo se sitúan dos bailes frente a frente y comienzan a tocar sus flautas simultáneamente, luego éstas se callan y los alféreces de los respectivos bailes comienzan a cantar en un contrapunto improvisado cuya temática se refiere a la alegría de encontrarse nuevamente y a preguntarse por la salud de los integrantes del baile.

Luego los bailes saludan uno a uno a la imagen, se forman frente a ella, tocan sus flautas y el alférez le canta agradeciendo por permitirles estar allí, frente a ella nuevamente.

Generalmente lo descrito demora casi toda la mañana. Una vez que ha finalizado esta parte se da inicio a la procesión; la imagen es sacada en andas del lugar en que permanece casi todo el año para que inicie un recorrido por las calles del pueblo. Ella encabeza la procesión, seguida por el baile dueño de casa y por todos los demás bailes, quienes recorren el pueblo tocando y danzando, todos al mismo tiempo. 
La imagen es dejada en un altar situado en la cumbre de un cerro o a la orilla del mar, donde los bailes, por separado, le rinden su homenaje.

Luego la imagen es devuelta en procesión a su lugar original, donde los bailes se despiden de ella. A medida que los bailes terminan esta parte del ritual, comienzan a despedirse del baile dueño de casa (de la misma forma en que lo hicieron durante el saludo, pero con una tématica referida a lo bella que estuvo la fiesta y a la esperanza de encontrarse nuevamente) para luego volver a sus respectivos pueblos.

Dependiendo de la fiesta, los organizadores suelen ofrecer un almuerzo o comida a todos los participantes, es el "recibimiento", consistente en almuerzo comunitario que reúne tanto a los chinos como a sus acompañantes. Durante él los chinos suelen conversar acerca del sonido de las flautas de determinado baile, de cómo tal baile está sonando bien o mal y de temas cotidianos.

\section{MúsiCa InSTRUMENTAL DE LOS BaILES CHINOS. CORPUS TEÓRICO MUSICAL}

La música instrumental de los bailes chinos se basa en el desarrollo de un concepto sobre todo armónico, vertical, en que dos grandes masas de sonidos se suceden unas a otras, formando un espacio sonoro con una inmensa gama de sonidos superpuestos.

Los instrumentos usados para generar esta música son las "flautas de chino", instrumentos de madera o caña cuya construcción interior del tubo, debido a una técnica compleja, permite al ejecutante emitir no sólo una nota sino un acorde disonante en cada soplido. Este sonido es llamado "rajado" por los chinos y es un elemento fundamental dentro del marco general de la música.

La flauta de chino es una flauta de un tubo, sin orificios de digitación, que se sopla a manera de zampoña. El diámetro interno del tubo está dividido en dos secciones, dejando un descanso entre ambos; esta conformación produce un sonido formado por dos notas fundamentales y una gran cantidad de armónicos agudos altamente disonantes.

La ejecución de la música está dada por una banda de flauteros --entre 10 y 24- divididos en dos filas paralelas, que soplan sus instrumentos de manera conjunta, todos los de una fila primero y todos los de la otra después, a manera de respuesta, formando una sucesión interminable de dos grandes masas armónicas con un ritmo sostenido de $2 / 4$ que es marcado por un bombo y un tambor. El tañedor del bombo (bombero) se sitúa al centro y atrás, cerrando el grupo, y el tamborero en el medio, entre ambas filas de flauteros.

Cada hilera de flautas está dispuesta de mayor a menor, es decir las que están situadas al comienzo son más grandes y dan un sonido de tonos graves ("flautas punteras"), y así van decreciendo en su tamaño hasta llegar a las 
llamadas "flautas coleras", ubicadas al final de la fila y que dan sonidos mucho más agudos.

El esquema general de la música es mantenido durante largos períodos de tiempo -entre tres y seis horas o más- en el que se observan sutiles variaciones en cuanto a las maneras de tocar.

Es interesante notar que, a pesar de la sensación de monotonía que una primera aproximación auditiva causa a un oyente occidental, existe una gran riqueza y variedad de sonidos, una dinámica que un oído atento va descubriendo poco a poco.

Hay diversas maneras de tocar o "tañíos"; la manera más común es mantener un pulso parejo, alternando las filas con un sonido fuerte y rápido casi stacatto, cada fila marcando claramente su pulso sin sobreponerse a la fila contraria, formando dos masas diferenciadas de acordes que se suceden.

Otro "tañío" consiste en hacer una disminución gradual del pulso y de la intensidad, tocando notas largas, superponiéndose el sonido de una fila sobre la otra, ambas filas fundiéndose en un sonido suave, creando una sensación auditiva muy especial. En este tipo de toque, al finalizar cada tañido $-\mathrm{y}$ debido a la reducida intensidad del soplo - se puede transformar el sonido rajado en un sonido más "puro", dado por alguno de los armónicos que conforman el sonido rajado, y que, mezclándose unos con otras provocan melodías sugerentes, melodías casi imperceptibles para los espectadores pero fundamentales para el chino.

Un tercer tipo de tañío - usado muy pocas veces y sólo cuando se entra a un templo - es el llamado "bombeo", que consiste en un sonido pianísimo no "rajado", sólo los armónicos de la flauta haciendo melodías, muy suaves, superponiéndose unas sobre otras y formando un espacio auditivo muy sutil que reverbera en las paredes del templo. Este sonido hace luego un "crescendo" que pasa por el segundo tipo de tañío descrito y sigue subiendo hasta llegar al tañió más común, fuerte, "rajado" y rápido.

Por otro lado, son importantes las variaciones en el pulso; un buen baile no se mantiene siempre en un mismo pulso sino que hace variaciones en la velocidad,va matizando entre pulsos rápidos y lentos, acelerando y disminuyendo, subiendo y bajando, manteniendo siempre una dinámica que fluye entre los dos tipos extremos de tañíos. Se debe "bajar el baile" para que éste se controle y los flauteros puedan descansar para luego volver a subir

"van bajando,subiendo despacito, dentran apagaíto así...volumen bajo y alto"

(Daniel Ponce, constructor de flautas, El Venado).

Un baile que no hace estas variaciones no es bien visto por los conocedores, por los chinos viejos, y además corre el riesgo de que los chinos no aguanten el esfuerzo físico y no puedan acabar en buena forma la procesión. 
"pucha pero mire, no, eso no sirve, ná que ver, mire, siempre igual, no, na que ver" (Daniel Ponce, constructor de flautas, refiriéndose a un baile que mantiene un pulso fijo).

El tamborero es fundamental en la dirección del baile; él es quien señala los cambios en la dinámica, quien comienza y guía las aceleraciones o disminuciones de pulso, los cambios de intensidad y los cambios de la danza, todo normado a través de un código de movimientos que efectúa con el tambor. Esta tarea es compartida con el "chino puntero", el que está primero en cada hilera, chinos experimentados que dan seguridad al baile en los momentos difíciles, como cuando se encuentran dos bailes y es necesario mantener el pulso y no perderse con el pulso del otro.

"el puntero es el maestro, si no, jodió todo. El tamborero también, él también tiene que llevar la misma medida, por eso que van los punteros con el tamborero mirándose....la persona que va a la punta no tiene que aflojar, sobre todo cuando se encuentra con otro baile..., si no pierde el tañió altiro."

(Lolo Guzmán, chino del baile de El Granizo, Olmué.).

"el tamborero tiene que ver las filas po, ver toda la fila, ver todo primero tamboreando y revisar la fila como está, todas esas cosas, pero siempre que vayan coordinados los chinos"

(Daniel Ponce, constructor de flautas, El Venado).

Dentro del conjunto de flautas existe un tipo especial, llamadas "catarras" o "Iloronas", que tienen un papel muy importante en la conformación del sonido de un baile chino. Estas flautas, que son tocadas sólo por un individuo de cada hilera, dispuestos frente a frente más o menos en una posición intermedia de cada hilera, producen un sonido especial — debido a la proporción interior del tubo y a la manera en que es tocada - conocido como "gorgoreo". Las catarras son tocadas alargando el sonido de tal manera que se superponen una sobre otra formando un sonido continuo que se escucha por sobre las dos masas de acordes que se suceden en un interminable $2 / 4$, produciendo un sonido general que es reconocido como muy bueno y escaso por los chinos.

Estas flautas no son tocadas permanente como todas las demás, sino esporádicamente, con silencios que al ser interrumpidos hacen destacar aún más su participación en el conjunto

"hay una flauta que la hacen como gorgorear...gargantear que le llaman, dan un ritmo rrrrrrrr, largo cuando van compactas, suena esta larga y la otra larga...sobresale porque es largo el sonido, 
llorona la llaman, es más lento...hay una que la hacen llorar, son chiquitas, lo hace perder a otro baile esa flauta, se pierde el ritmo".

(Arturo, chino del baile de La Laguna).

"hay unas flautas así, chicas, le llaman coleras, y aquí se llaman catarras, entonces se van pasando así el sonido de una a otra y ahí van perdiendo a los bailes, se pasan haciéndola largo (el tañío), se pasa a la otra, se mezclan y hacen un runruneo".

(Armando Reyes, chino del baile de Cai Cai).

Los cultores de esta tradición tienen un corpus teórico musical bastante rígido que les permite diferenciar claramente los sonidos que son aceptados y que forman parte de la tradición y los que quedan excluidos.

Los chinos viejos poseen tal grado de discriminación del sonido que son capaces de decir, sólo escuchando, cual es el baile que está tocando de entre todos los que hay en la fiesta. Existe un claro concepto de goce estético, el sonido de las flautas es bonito, los cultores se emocionan escuchando el sonido de un "buen baile". Expresiones como "esa flauta pitea" o "ese parece sonido de botella" se escuchan denotando que el el sonido del baile en cuestión no es bueno, mientras que expresiones como "mira como gansea" (un buen sonido de flauta es parecido al graznido de los gansos) es un comentario de aprobación.

La división del diámetro del tubo de la flauta debe ser realizada en un punto exacto para que se produzca el sonido deseado. Si el sonido que da una flauta no es perfecto se trabaja nuevamente sobre ella, y si esto tampoco da resultado va a parar al fogón en que se calientan los fierros para hacer nuevas flautas.

La construcción de este tipo de flautas es un arte transmitido de padres a hijos y es un oficio actualmente dominado por muy pocas personas

"son maestros que los años les han enseñado la profesión, han hecho muchas... es muy importante un buen instrumento, un baile que no anda con buenos intrumentos es pa' la risa, pa' los otros bailes es pa' la risa"

(Marcelo, ex chino del Baile de Maitencillo).

Es importante mencionar que la estética musical de la música instrumental de los bailes chinos es absolutamente ajena y contraria a la europea, es decir, se trata de una manifestación que, en lo estrictamente musical, está relacionada a las poblaciones indígenas que habitaban la zona central de Chile antes de la llegada de los españoles.

Las diferencias estéticas entre la música instrumental de los bailes chinos y la tradición occidental son muy profundas. Mientras la primera presenta 
sonoridades distorsionadas a través de una desafinación controlada, acordes no tonales, armonías superpuestas, polifonías aleatorias que presentan polirritmos cambiantes, superposición de armonías tímbricas, sin uso de melodía, la segunda busca sonoridades afinadas con precisión y carentes de distorsión, una estructura fuertemente tonal basada en la melodía y polifonías muy coordinadas que evitan toda aleatoriedad de polirritmo.

\section{MúsiCA Y ESTADOS ESPECIALES DE CONCIENCIA}

El término "estado especial de conciencia", también llamado "trance", "éxtasis" o "estado alternativo de conciencia", es bastante difícil de definir debido a que envuelve un mundo totalmente subjetivo, pero existe consenso en que se caracteriza, entre otras cosas, por un sentimiento de disolución y unidad con el universo, sensación de vuelo, de separación del cuerpo, sentimiento místico y de encuentro con el plano divino, etc. ${ }^{3}$

El acceso a ese tipo de percepción de la realidad es alcanzado por medio de la ingestión de sustancias psicoactivas y/o de diversas técnicas como son la danza continua por períodos prolongados de tiempo, el autosacrificio, el ayuno, la meditación, las vigilias continuas, repetición de mantras y oraciones y ciertos tipos de música. ${ }^{4}$

En América la música ha tenido una importancia fundamental como parte activa dentro del sistema religioso. La técnica más comúnmente usada por los chamanes para alcanzar un estado especial de conciencia ha sido el canto y la música; música repetitiva que es ejecutada durante horas o días permitiendo al chamán abrir la puerta hacia el otro mundo, y una vez dentro de él, guiar el viaje para obtener los resultados buscados. ${ }^{5}$

La relación existente entre la música y la danza como agentes inductores de estados de trance ha sido estudiada por Rouget, Neher, Kartomi y Erlman entre otros, mostrando que éste es un fenómeno común en diversas culturas de diversos lugares del mundo.

La música de los bailes chinos, inserta en un sistema ritual bien definido, podría ser, debido a sus características, una manifestación musical cuya estructura permite inducir un cambio en el estado de conciencia de quienes participan directamente de él.

\footnotetext{
${ }^{3}$ Ver Eliade 1960, Halifax 1979, Harner 1976, 1977, Zinberg 1977, Marsh 1977, Singer 1977.

${ }^{4}$ Ver Rouget 1980, Eliade 1960, Schultes y Hoffman 1982, Halifax 1979, Harner 1976.

${ }^{5}$ Ver Dobkin de Ríos 1975, Whitten 1979, Stevenson 1968, Martí 1961, Hart 1990.
} 


\section{FACTORES EMOCIONALES Y FISIOLÓGICOS PRESENTES EN EL RITUAL DE CHINOS}

Hay varios aspectos que se interrelacionan en un ritual de chinos de tal manera que crean una red de factores que influyen sobre aspectos fisiológicos y psicológicos de quien está participando directamente del ritual. La interrelación de estos factores crea las condiciones necesarias para que se produzca un cambio a un estado especial de conciencia.

Este capítulo intenta analizar - linealmente y por separado - cada uno de estos factores, pero debe entenderse que todos ellos confluyen y suceden al mismo tiempo.

Estos factores son: la hiperventilación, el espectro sonoro (saturación sonora), el esfuerzo físico mantenido durante horas provocado por la danza y el tañido, la presión psicológica, las palabras muy sentidas del alférez, repetidas a coro por los chinos, la significación del ritual y el consumo de alcohol.

Para lograr el "sonido rajado" - fundamental a todo baile chino- es necesario soplar una cantidad enorme de aire sobre cada flauta (una cantidad e intensidad de soplo que no tiene ningún punto de comparación con el requerido para hacer sonar cualquier instrumento de viento occidental) lo que implica realizar un gran esfuerzo físico con un estado de hiperventilación mantenido durante horas sin parar.

El tiempo entre soplo y soplo alcanza apenas para respirar, lo que implica que además de expeler con mucha intensidad una gran cantidad de aire, el chino está obligado a inspirar rápidamente pues de lo contrario pierde el pulso y podría comenzar a tocar junto con los de la hilera contraria.

El estado fisiológico producido por la hiperventilación es conocido como síndrome de hiperventilación y se explica en términos de cambios bioquímicos en la composición de la sangre, como un aumento de la alcalinidad y una disminución de la ionización del calcio. (Grof, 1988).

Los efectos psicológicos de la hiperventilación han sido muy bien estudiados por el psiquiatra checo-norteamericano Stanislav Grof, quien ha desarrollado una terapia llamada "respiración holotrópica" para la inducción de estados especiales de conciencia. A partir de este trabajo ha podido observar que "el aumento de la frecuencia y de la profundidad de respiración ablanda las defensas psicológicas y lleva a la liberación y emergencia del material inconsciente (...) El individuo puede ser inundado de sentimientos de amor y de conección mística hacia otras personas, la naturaleza, el cosmos y Dios" (Grof, 1988, p.171)

$\mathrm{Al}$ estado de excitación física y mental producido por estos factores se suma el sonido de la propia flauta multiplicado por el sonido de las flautas de su hilera y el de las de la hilera contraria, además del sonido de los bailes que preceden y que suceden a su propio baile. El sonido de los bailes de chino es complejísimo y a partir del choque de la gran cantidad de armónicos que llenan 
el espacio se producen nuevos sonidos, "melodías fantasmas" que se van superponiendo, formando ciclos que se repiten para dar paso a otros nuevos creando un efecto impresionante en quienes tocan o escuchan. El chino está inmerso en un mar de sonido, en miles de capas de sonidos que se superponen y lo traspasan provocándole un estado de percepción muy especial.

"el sonido es casi lo principal, el sonido, se emociona y todo, así como atrae a la gente y uno cuando baila y toca y toca lindo una flauta atrae más, le da ganas de seguir más bailando y se emociona también, el mismo sonido de la flauta..."

(José Ponce, chino del baile de Quebrada de Alvarado).

Cuentan los chinos que hay personas que son afectadas tan fuertemente por el sonido de estas flautas que - siendo sólo espectadores- han comenzado a sentir un malestar general debido a la intensidad y cualidad del sonido, hasta llegar a desmayarse, y otras que con sólo asistir al ensayo de un baile no han podido dormir durante dos noches pues cada vez que lo intentaban escuchaban el sonido de las flautas.

La música de los bailes chinos es percibida por sus ejecutantes en un esquema general de repetición infinita del pulso y de una alternancia constante de las dos grandes masas armónicas que se suceden, con una gran intensidad de volumen. Es importante también la cualidad del sonido, es decir, el rango y timbre de la trama de sonidos que producen las flautas, una saturación de casi todo el espectro sonoro por medio de la superposición de capas de sonidos que producen algo similar al "ruido blanco" (el sonido del agua de un río caudaloso.) Pareciera que la hipersaturación de sonidos, es decir, el uso simultáneo de todo el espectro armónico o de una gran parte de él durante un período prolongado de tiempo y la repetición constante del mismo produce un cambio del estado cotidiano de conciencia a otro nivel en que es posible percibir la realidad de una forma completamente diferente a la cotidiana.

La importancia del sonido y la alta carga emocional que éste produce se hace evidente en las palabras de José Ponce, chino del baile de El Tebal:

"a mí me dan ganas de llorar cuando ha bajado así, lo más que me encanta cuando entramos a la iglesia de aquí de Las Palmas, nosotros entramos ¿se acuerda?, con una cuestión bajita, un sonido bajito..."

Nota de campo:

Ir a la fiesta de Pachacamita y entrar en el sonido, 300 flautas cuelgan desde el aire y reptan por mis labios haciendo una polifonía alucinante que rompe cualquier estructura mental. El baile de Ventana junto al de Petorquita hacen que los ojos sean absurdos, caminar entre ambos 
sonidos es flotar en lo indescriptible, la luna se para con los cachos hacia arriba, el alférez pide por la salud de un compañero de la hermandad que está enfermo, la feria se agolpa en la calle de tierra y polvo, el sol entibia el verde que nos rodea, el río Aconcagua, los cerros verdes de hierba y cielo, un día increible para esta increíble fiesta; a 100 el maní, a 100 el helado, heladito güeno aquí, sacar y chupar, sacar y chupar, la procesión avanza entre olores a fierritos, cabritas, empanadas y cuanta cosa hay, los chinos suben bailando y tocando la colina donde se cantará a la Virgen del Carmelo, la fe inmensa en los rostros, en las piernas que suben y bajan, en estas flautas que hacen temblar el espacio. Cerrar los ojos y flotar en este infinito de ritmos, cerrar los ojos y dejarse llevar por este sonido apocalíptico, este sonido que lo encierra todo, este sonido que te levanta y te baja y te inunda para llevarte flotando a abrir todas las puertas, todas...

(Fiesta de la Virgen del Carmen, Pachacamita, julio de 1992).

La música de los bailes chinos está indisolublemente ligada a la danza. Los flauteros de ambas filas y el tamborero hacen una danza muy característica mientras tocan, consistente en una serie de saltos acrobáticos y pasos que requieren de un gran esfuerzo físico, agachándose y levantándose sin parar, siempre al ritmo de la música, haciendo diversos movimientos coordinados que son dirigidos por el tamborero, y que por momentos - algunas veces bastante largos - son realizados con una rapidez extrema.

El nivel de esfuerzo físico requerido para bailar con una intensidad tan fuerte durante un período prolongado de tiempo es tal, que se convierte en motivo de preocupación y de bromas para algunos chinos, que saben que se arriesgan a calambres y a dolores intensos durante la procesión y en los días posteriores a cada fiesta.

De hecho, hay chinos que abandonan su puesto en medio de la procesión porque sencillamente no resisten el esfuerzo y los dolores musculares, aun sabiendo que el abandono significa la burla de sus compañeros y una caída en su estatus de chino no sólo ante el baile sino ante la comunidad

"lo único que al otro día duelen las piernas, aquí, los muslos duelen, chii si uno a veces queda como andando curco, una vez el Juan tuvo que cagar parao, no podía doblar las piernas, se agarró a la cola de un burro y cagó parao".

(Armando Reyes, chino del Baile de Cai Cai). 
Nota de campo:

y entre vasos de mistela vamos conversando y riéndonos y Armando comienza a decirme que mañana me voy a morir, que no voy a ser capaz de aguantar saltando toda la fiesta, voy a llevar una carreta con un burro pa cuando te caigai, si el asunto no es así no más, si es jodio oh, y así todos molestándome y riéndose porque no seré capaz de saltar todo el día, que los calambres, que el cansancio, ahi te quiero ver pu Claudio y yo diciéndoles que mañana en la noche me reiré yo, que ya verán como lo hago perfectamente, pero no, si la custión no es broma Claudio, chii, ahi vai a ver lo que es gueno, y yo en realidad estoy totalmente seguro que el asunto físico no es problema para mí, que saltaré sin problemas todo el día, el único detalle es lo que me pasará en la cabeza, a donde diablos iré a parar en medio de ese mar de sonido, mi preocupación es ésa y no el físico, y ahí los chiquilines insitiendo que sólo voy a durar un rato y luego tendré que salirme, metiendo todo el miedo posible, contando anécdotas peliagudas sobre chinos que han quedado tirados, etc., atardece, llega más gente, todos se van enterando de que bailaré y se van sumando a las bromas; no, no va a poder, se va a quedar en la mitad, ayayaii, mañana vamos a ver al chino santiaguino pue.

...Estoy totalmente mojado, el sudor entra a chorros por mis ojos y cae por el cuerpo como una lluvia, la camisa pegada al cuerpo, las piernas pegadas a los pantalones, subir y bajar, bajar y subir, tocar, tocar y tocar, todo es tocar y escuchar y estar metido en esta cosa increíble que es una fiesta de chinos, finalmente estar adentro y no mirando, ser un chino es una de las cosas más impresionantes que he hecho en mi vida, nada que pensar, no hay pensamientos mientras toco y bailo y escucho esta flauta catarra que sopla el chino que baila a mi lado y que suena exquisitamente, la vida y la muerte en un baile chino, el sol es tremendo pero da lo mismo, el calor es inmenso pero da lo mismo, todo es bailar y mirar al tamborero y seguir sus pasos y tocar, tocar inmerso en ese sonido apocalíptico que me traspasa y me lleva y me levanta y me agacha a unos 50 metros de la gruta - cuando estamos tocando cada vez más intensamente - comienza a dolerme el costado del estómago, el bazo o algo así, como cuando chico corrías demasiado y ya no daba más, el asunto duele $y$ duele $y$ va en aumento, me falta el aire mientras subimos la escalera que nos lleva a la gruta pero no dejo de tocar, sé que ahora - frente a la virgen - viene lo más intenso de todo, tocar hasta reventarse con esos acelerandos y mudanzas rápidas, el dolor del costado es muy intenso y me digo ya claudivarius, has llegado hasta aqui y no vas a abandonar ahora, justo ahora; el dolor no existe, 
todo es una flauta y un baile, nada más, nada más existe, sólo escucha, escucha este sonido, nada más, y el dolor desaparece completamente, una vez más la mente regulándolo todo y ya estamos frente a la virgen tocando endemoniadamente fuerte y rápido, el último esfuerzo, el último tramo y ya, tocar como si el mundo estuviera reventando, hacer un ralenti y comenzar nuevamente con una velocidad que apenas da tiempo para respirar, pegados al suelo saltando de pierna en pierna hasta que comienza a cantar el alférez y nosotros -flauta apoyada sobre el pie derecho- nos inclinamos haciendo el coro con el corazón ya salido por la boca...

(Fiesta de la Virgen de Cai Cai, noviembre de 1992).

Por otro lado, es importante la repetición constante del movimiento, la estructura general de la danza de chino implica moverse hacia arriba y hacia abajo, subir y bajar haciendo el mismo movimiento con el cuerpo durante horas, lo que provoca un estado casi hipnótico en los participantes.

A la tensión física se agrega una tensión psicológica ya que es necesario mantener permanentemente un alto nivel de concentración mientras se chinea, pues puede bastar una mirada hacia otro baile para que el chino pierda el tiempo de su tañido o pierda el paso del baile. El chino debe mantener fija su atención auditiva y visual sólo en su baile, debe estar atento al tamborero para ver cuál es la "mudanza" que viene y para saber los cambios en la dinámica del tañío. ${ }^{6}$

Dentro de los pulsos de todos los bombos que suenan simultáneamente y a diferentes tiempos el chino debe hacer un gran esfuerzo de concentración para escuchar sólo el que corresponde a su baile y seguir ese pulso determinado y no los otros.

“...si usté es nervioso, el otro rápido que está al lado lo pierde, si usté no se preocupa de él, se preocupa de lo que está haciendo no más, no lo puede perderlo..."

(Lolo Guzmán, chino del baile de El Granizo)

“...Cuando se pone a pajarear uno, ahí es donde se pierde, pero ya uno que está acostumbrado va mirando al compañero, aunque tenga cualquier cantidad de bulla..."

(Arturo, chino del baile de La Laguna).

\footnotetext{
${ }^{6}$ Mudanza es el término con que se refieren a los distintos tipos de pasos que realiza el tamborero y que los chinos van repitiendo. Antiguamente un buen tamborero podía saber más de cien mudanzas, actualmente la cantidad de mudanzas empleadas es mucho menor.
} 
Esta presión psicológica es aumentada por el hecho de querer estar entre los que mejor chinean en su baile, hay una lucha por querer ser reconocido socialmente como un "chino bueno" dentro del baile y esto lo lleva a esforzarse lo más que pueda. Por otro lado, el chino está representando a su comunidad ante otras comunidades y debe hacerlo en buena forma, debe tocar bien y sonar más que los otros bailes, tiene una responsabilidad social que cumplir y eso hace que se esfuerce todo lo posible para dar lo mejor de sí.

"ah, te agarraron los nervios, te agarró el nervio po, pero despué se pasa, a mí una vez me agarró y era tan fuerte que no podía sostener la flauta en la boca, me tiritaba así, sabís lo que pasa que es tanto lo que uno quiere sonar más que los otros que le da un nervio así a uno, como que lo agarran los nervios a uno, eso es lo que te pasó a ti.... pero es la primera vez no más, a mí me pasó una vez que estabamos chocando con otro baile y esa custión que querís sonar más que el otro y no querís que el otro suene más y soplai con todo y ahí me agarró el nervio, fuerte, si no podía sostener la flauta, pero después se me pasó".

(Armando Reyes, chino del baile de Cai Cai).

Otro punto fundamental en el contexto ritual de una fiesta de chinos es el "alférez", personaje que acompaña al baile y que es el encargado de representar -por medio del canto dirigido a la imagen - tanto al baile como a la comunidad. En este canto, que es en parte improvisado y en parte memorizado, el alférez da las gracias a la divinidad por permitirles estar allí nuevamente, pide por lluvias, por buenas cosechas, por los enfermos, por un buen año, pide protección divina, canta historias bíblicas relacionadas a la celebración que se está llevando a cabo, etc. Es el mediador entre los chinos y la divinidad, entre la comunidad y la divinidad.

Las palabras del alférez, cargadas de mucha emotividad, son repetidas a coro por los chinos, quienes han bailado y tocado sin parar sus flautas hasta este momento de canto en que se produce una relación verbal con la divinidad, se le pide directamente por la solución de problemas concretos, como en el siguiente canto:
"a mí me causa dolor vine a celebrar tu día pido al dios vivo de los cielos que me dé la mejoría
para no cortar la guía mi memoria siempre lo anhela pido yo por un vasallo 


\author{
del baile de las hijuelas \\ del baile de las hijuelas \\ en este precioso día \\ enfermo de una pierna \\ dale pues la mejoría \\ yo no sé cómo sería \\ nuestra madre del Carmelo \\ aquí me encuentro clamando \\ al dios vivo de los cielos \\ la fiesta es pues muy bonita \\ con el baile de san Nicolás \\ y todo lleno de fe \\ te pido la sanidad \\ me retiro para atrás \\ bien me pueden disculpar \\ si nos das la mejoría \\ te volveremos a cantar \\ hasta aquí voy a llegar \\ con gusto en el corazón \\ pido al dios vivo de los cielos \\ échanos la bendición..." \\ (Alférez Carlos Bernales, fiesta de Pachacamita 1992).
}

La intervención del alférez se produce primero para saludar a la imagen que se está celebrando, luego comienza la procesión y el alférez interviene nuevamente cuando la imagen es dejada en el altar situado en la cumbre de un cerro o a la orilla del mar, donde le canta a la imagen, le pide y le agradece. Luego la procesión vuelve cargando a la imagen hasta dejarla en su lugar de origen, donde interviene nuevamente el alférez, despidiéndose de ella.

Las palabras del alférez tienen una connotación emotiva muy fuerte que realza el momento especial que se vive durante las fiestas; a la imagen sagrada se le habla desde lo profundo, desde lo más interno, desde aquel lugar que difícilmente se exterioriza durante la vida cotidiana
"para la vuelta del año
no me puedo dividir
ninguno de los presentes
'tamos seguro 'e venir
'tamos seguro "e venir
por lo que los libros encierran 
el día menos pensado

nos puede tapar la tierra

nos puede tapar la tierra

así lo explica mi voz

y se cumple aquí el adagio

hoy somos, mañana no

hoy somos, mañana no

porque escriturao está

pues somos en este mundo

una sombra y nada más"...

( Arturo Ogaz, alférez del baile de Ventana, Fiesta de San Pedro, Higuerillas.)

Una instancia diferente de participación de los alféreces es al comienzo de la fiesta cuando ocurre el saludo entre los diferentes bailes participantes; los alféreces se saludan cantando en forma alternada, contrapuntística, preguntándose mutuamentente por la salud y alegrándose de estar una vez más juntos en una fiesta. Este encuentro se repite al final de la fiesta cuando los bailes se despiden entre sí. Estos momentos son también importantes en términos emotivos para los alféreces, como lo explica el tamborero del baile de Ventanas:

"y él (el alférez) me decía que cuando se saludan los alférez, pucha, y ahí se saludan y se ven y ya se conocen porque se han encontrado en tantas fiestas y cuando se saludan se emocionan y llegan a llorar".

Por otro lado, la presencia de la imagen sagrada es un factor importante para el chino, que en ese estado especial de emotividad en que se encuentra mira a la representación de la divinidad y toca y danza para ella, muchas veces pagando alguna manda o pidiendo algún favor especial en el que se le va la vida.

La relación que se produce entre el chino y la imagen es muy fuerte y es claramente expresada en este canto de alférez:

"Por fin me llegó la hora con gusto lo digo yo y a ti madre de los cielos buenas tardes te dé yo te dije hoy en la mañana y no se me va a olvidar 
que aquí arriba de este cerro pues te iba a saludar

pena me causa en el alma y cantando te diré sólo son pequeños momentos que tengo de estar a tus pies

yo quisiera ser el sol para entrar por tu ventana para darte de besitos lucero de la mañana será que te quiero tanto yo no te olvido jamás para mí madre querida tú eres la flor perfumá la más hermosa del jardín te digo con gran amor tú eres la maravilla que habita en mi corazón corto va a ser mi saludo porque me sirve de ejemplo más allá te cantaré te voy a cantar en el templo hermosa doncella y pura madre de nuestro señor de toda esta concurrencia habita en su corazón soy un obrero del mar $y$ esto te voy a explicar y a esta tierra campesina te he venido a visitar de mi alma sale mi voz mi cantar del corazón de rodillas en el suelo échalos la bendición será hasta un momento más y esto te voy a decir pues te volveré a encontrar antes pues de despedir madre reina del Carmelo 
y mi voz que te venera

permiso madre adorada

y aquí doblo mi bandera"

(Alférez Luis Galdames, del baile chino de Ventana. Fiesta de Pachacamita 1992).

El chino no baila sólo porque le guste, el chino baila porque necesita bailar, porque lo siente en lo más profundo de sí...

"yo ya quería dejar de tocar, ya no quería salir más pero ayer cuando escuché que las flautas sonaban tuve que ir, sentí eso tan adentro, es una cosa que uno siente tan adentro y tuve que ir $\mathrm{y}$ ponerme a tocar, si yo soy chino po, si uno es chino y no es cuestión de llegar y decir ya no toco más, porque no se puede po.." (Carlos, chino del baile de La Laguna).

Nota de campo:

al fin bailo chino en el interior de una iglesia y todo es flotar en las esquinas, pasearse entre los santos y la virgen con esta música que sale desde el centro de mi alma y se expande y se pega a todas las tablas de este suelo, la noche me traspasa y me lleva tan atrás y vuelo de esta iglesia a la de Quilpué y a esa otra en la que se ha velado a mi padre y aquélla en que se ha velado a mi abuelo y en realidad las iglesias siempre han tenido esa carga nefasta para mí, el lugar al que se lleva a los muertos queridos, las personas que ya no podrás ver, que ya no podrás. y sin embargo hoy aquí en esta iglesia de Las Palmas de Alvarado entregando mi alma en una danza feroz y tocando y cantando como siempre quise hacerlo, reventar mis labios en este sonido en esta armonía gigantesca que me lleva y me sube a las palmeras de la entrada de la iglesia y desde alli al campanario y bajo por las paredes y me siento al lado del niño dios y sigo, sigo viajando en el sonido, recorriendo la iglesia, las velas, los fieles que entran de rodillas y sostienen estampas del niño dios, entro a la sacristia y salgo por la puerta que da al poniente, a la noche que se abre completamente sobre nosotros y nos hunde en cerros y vientos subterráneos, sigo, atravieso huellas y ojos, peumos, litres, caminos, rios, y vuelvo al lado de los chinos y a esta felicidad inmensa de ser un chino y tocar, tocar hasta que acabe el mundo mientras algo se produce entre la noche y mis pupilas y la virgen es más hermosa que nunca, más verdadera que nunca.

(Fiesta del Niño Dios de Las Palmas de Alvarado, diciembre de 1992). 
Los rituales de chinos se enmarcan actualmente dentro del contexto ceremonial católico y esto implica una relación bastante tirante en algunos pueblos, dependiendo de la posición más o menos ortodoja del cura local frente a estas manifestaciones de "religiosidad popular".En casi todas las fiestas el cura hace una misa pero a ésta asiste sobre todo la gente que acude a la fiesta como espectador, una gran parte de los chinos no participa de ella tal vez porque no la necesitan, porque el chino no necesita al sacerdote como intermediario entre él y la divinidad porque su comunicación es directa; se produce tocando, bailando y a través del canto del alférez, que habla de cosas concretas que les atañen a ellos directamente y que además, también sabe la Biblia.

Durante la fiesta los chinos suelen beber vino, mistela ${ }^{7}$ y cerveza, en cantidades variables según el baile.

Hay bailes que tiene fama de borrachos y efectivamente sus integrantes comienzan a beber desde temprano y lo hacen durante toda la fiesta, hay otros que beben en forma moderada y hay los bailes en que ningún chino bebe.

Los momentos en que los chinos beben alcohol no están normados: hay chinos que se salen de la procesión para "tomarse un trago" y luego vuelven a su puesto, repitiendo esta situación durante todo la procesión, hay quienes nunca abandonan el baile pero que beben durante el almuerzo o durante los momentos de descanso entre los saludos y la procesión y hay quienes miran con malos ojos a los otros chinos que beben.

La cantidad de alcohol ingerida, como ya se ha dicho, es variable, ésta va desde uno o dos vasos de vino en el almuerzo hasta una cantidad considerable de cervezas (entre 5 y 10) y una cantidad similar de vasos de vino.

Es común que algún acompañante de un baile regale un cajón de cervezas a los chinos en la detención que se produce en mitad de la procesión, luego de cantarle a la imagen, para que los chinos se refresquen antes de comenzar la última parte de la procesión.

En términos de porcentaje es posible decir que en una fiesta de chinos es común encontrar a un $5 \%$ de chinos en estado de ebriedad, un $60 \%$ que beben moderadamente y un $35 \%$ que no bebe.

Se bebe vino pues ayuda a dar fuerzas para aguantar el tremendo esfuerzo físico que es necesario realizar durante la procesión.

"Hay muchos que toman por los nervios, y se le quitan los nervios, muchas veces hay chinos nuevos y se ponen nerviosos, y se ponen a tiritar, pegán un picotón y se le calma, se normaliza la persona y le da más fuerza, más valor"

(Lolo Guzmán, constructor de flautas y chino de el baile de El Granizo).

\footnotetext{
${ }^{7}$ Mistela es una bebida preparada en base a aguardiente y agua hervida con palos de guindo y membrillo.
} 
Nota de campo:

tocamos durante la mañana y luego vamos a almorzar, todo el baile junto en una mesa larga, nos sirven cazuela con ensaladas y vino, voy a tomar jugo pero los chinos me dicen que no, que tengo que tomar vino para tener fuerzas para la procesión, el vino te va a dar ánimo y te va a tirar pa arriba si no no vai a aguantar, de ahi pa abajo saltando lo botamos todo, no vayai a tomar agua, no viste lo que me pasó recién cuando tomé agua, me dolió el estómago altiro y tuve que salirme un rato, asi que toma vino no más, y me van llenando el vaso mientras comemos esa exquisita cazuela.

El consumo de alcohol, mencionado en este trabajo como un elemento más que influye en la inducción de un estado especial de conciencia, presenta una situación particular. Debido a que no todos los chinos beben alcohol, es el único factor que no está presente en todos los participantes, pero que juega un papel importante en quienes hacen uso de él.

La ingestión de alcohol influye a nivel emocional en el participante, los sentimientos afloran y hay una entrega emocional y una desinhibición que es potenciada por éste. El alcohol actúa sobre el sistema nervioso central, sobre el córtex, liberando los centros y conecciones subyacentes, motivando la supresión de las inhibiciones. En la corteza cerebral se encuentran los elementos social y culturalmente aprendidos, todo lo que es aceptado y rechazado por la sociedad en que el sujeto está inserto. Por otro lado, la corteza actúa como un filtro inhibidor de los impulsos básicos y el alcohol actúa sobre ella inhibiendo ese filtro inhibidor, por lo que las emociones y los impulsos básicos quedan desligados del control que ejerce sobre ellos la corteza. (Huguenard, Jaquenoud, 1967.)

Todas estas características hacen del ritual de bailes chinos una instancia muy especial en términos emotivos para quienes participan directamente de él, creándose las condiciones emocionales y fisiológicas necesarias para producir un cambio a un estado especial de conciencia.

\section{ESTADOS ESPECIALES DE CONCIENCIA EN UN RITUAL DE CHINOS}

"una sensación extraña, yo una vez me disolví en la música, o sea, como que yo era la música, nada más importaba"

(Marcelo Gonzales, ex chino del baile de Maitencillo)

Si bien no existe un corpus de normas que explique los cambios a nivel de conciencia que se producen en un ritual de chinos y al parecer los participantes no racionalizan los estados especiales de conciencia que se producen en ellos, hay ciertas vivencias descritas por los chinos que llevan a pensar que éste se 
produce a un nivel subconsciente siendo una experiencia tan extraña y personal que no es compartida con los demás, aún entre los propios integrantes de un mismo baile. (Sobre este punto y algunos problemas que presenta hablaré en las consideraciones finales).

La forma en que comúnmente se produce esta alteración tiene varias etapas; al comienzo de la "chineada" se produce una sensación de malestar que es llamada "emborrachamiento", y que es provocada por el comienzo de la hiperventilación; se siente un mareo, como un vahído, un hormigueo generalizado, una especie de corriente que recorre el cuerpo

"como que anda en otra, está así uno con la cuestión..., como que andaba así como en el aire, así el cuerpo como helado, como un agua así, una cosa así, cuando flautea... como de la cabeza pa abajo, corría como una aguita y después ya entra en calor uno pa flautear y ya después se le quita po...,esa cuestión como que le da un hormigueo en los piernas, en el cuerpo así, como que dan ganas de salirse altiro (de la filla) pa que se le quite, ese día por eso me salí yo, cuando estuve en la fila después me salí pa allá, me salí un rato y me senté un rato y le hacía a los pies en el suelo pa que se me quitara y no pasaba ná po... desagradable, fue desagradable una cosa así, de repente".

(Guillermo Zamorano, chino nuevo, del baile de Quebrada Alvarado).

"Cuando uno empieza a bailar se emborracha pero es al principio no más, una vez que se pone a bailar, que se pone a saltar ya se le pasa altiro y ahí sigue no más..."

(Armando Reyes, chino del baile de Cai Cai).

“...después se pasa, ya después no siente más, yo creo que aonde entran en calor los huesos ya no siente niuna cosa ya,...en too caso yo creo que tiene que ser así..."

(Guillermo Zamorano, chino del baile de Quebrada Alvarado).

Nota de campo:

me pongo el gorro y mojo mi flauta mientras un nerviosismo feroz me invade completamente, ya chiquilín, llegó la hora, a soplar no más y que sea lo que sea, ya estoy tercero en la fila y comenzamos a soplar yendo hacia la gruta, al minuto de estar soplando como demente comienzo a sentir una corriente espantosa que me atraviesa todo el cuerpo, como enchufado a una línea de alta tensión, el baile no es muy movido aún y siento que necesito moverme para descargar 
esta corriente espantosa que circula por todo el cuerpo, poco a poco la corriente desaparece de mis piernas y me da con una intensidad feroz en los brazos, siento un hormigueo tan fuerte y desagradable en los brazos, como esa sensación de cuando se duerme una parte del cuerpo pero multiplicado por mil, sé que si muevo los brazos disminuirá pero no puedo moverlos porque estoy bailando chino y no se mueven los brazos, la corriente comienza ahora también a inundar mi cara, tengo todo el rostro traspasado por este hormigueo horrible, nadaque hacer. esperar a que se pase porque en algún momento tendrá que pasarse, pero ¿y si no se pasa? seguir soplando y saltando mientras subimos la escalera hacia la gruta y la corriente no hace ningún amago por disminuir, comienzo a mover los dedos de la mano izquierda para dar alguna salida a toda esta energia perono consigo nada, nos acercamos a la virgen y paramos abruptamente pues el baile de Pachacamita la está saludando y debemos esperar nuestro turno, esta parada en seco hace que la corriente aumente aún más, comienzo a mover lo más disimulado que puedo las piernas, los brazos y los dedos para descargar algo de esto que me arrasa, le digo a un chino viejo que está a mi lado lo que me pasa y me dice que sí, que es la presión que se tiene que regular, veís que hay un cambio de presión cuando uno empieza a tocar pero después se te va a pasar, una vez que se regula ya se te pasa, y yo por mientras con esta cosa horrible en mi cuerpo, totalmente sobrepasado, sobregirado, esta inmen sa corrienteque va cediendo poco a poco ahora que hemos dejado de tocar, el hormigueo se va haciendo menos potente y sigo haciendo movimientos lo menos notorios posible para que todo fluya y salga de mi cuerpo, los chinos de pachacamita continúan saludando a la virgen y nosotros parados esperando el turno, ya ha pasado la corriente y estoy tranquilo, los pachacamita terminan su saludo y nos toca a nosotros; comenzamos a soplar nuestras flautas como dementes y ese sonido exquisitollenando el aire, ya viene la corriente nuevamente, me va invadiendo desde los brazos al tórax, al estómago y a la cara, la única parte del cuerpo que se libra son las piernas que están en constante movimiento, subimos el final de la escalera y llegamos frente a la gruta y ahi tocamos un buen rato mientras esa corriente me sacude totalmente, intento no hacerle caso pero es inútil, es una sensación demasiado fuerte y desagradable, dejamos de tocar y el alférez comienza a cantar, la corriente me sobrepasa totalmente pero al cantar el primer coro disminuye un poco, luego al seguir cantando se va yendo lentamente, a la quinta cantada y a ha desaparecido. toda la corriente se va en ese canto hermoso y con toda el alma, esa repetición de las dos últimos versos de la cuarteta del alférez, la cabeza me palpita como si fuera a estallar pero la corriente ha cedido, se ha ido con el canto, yo suponía que esto tenía que ser así, 
que el canto actuaría como un cable a tierra que descargaría el exceso de energía, y claro, eso es lo que pasa, nada mejor que cantar en un coro a grito pelado para regular esa corriente espantosa; de la teoria a la práctica chiquilín, ese es el asunto.

(Fiesta de la Virgen de Cai Cai, noviembre de 1992).

le cuento a don luis - que fue chino durante muchos años-sobre la corriente que me da cuando chineo, le pido consejo de chino nuevo a chino viejo, y me dice que sí, que a él también le pasaba a veces, que le chirriaban los oidos y la cabeza le daba vueltas, entonces hay que salirse un rato y ahí se pasa y después se vuelve a la fila, el ejercicio será pue.

le pido consejo a don Ignacio sobre la corriente y me dice que es la presión y que tengo que chupar limón, el limón es muy re gueno pa la presión, usté se lo lleva en el bolsillo y ahí cuando le viene la custión lo chupa y se le va a pasar, es la presión que cambia con el ejercicio pero el limón es muy re gueno, ahí yo le dí a la iñora unos limones pa que trajera asique ahí le paso uno y con eso va a estar bien.

Al comienzo de la chineada no se baila, hay algunos minutos en que sólo se toca las flautas y es ahí donde se produce el mayor "emborrachamiento", pero una vez que comienza la danza, que el cuerpo comienza a moverse esa sensación desaparece y después de un tiempo tocando sin parar aparece otra que es bastante difícil de explicar para ellos

"es bien personal... ellos sienten las cosas igual como tú pero es difícil conversarlas... no te lo pueden expresar bien, incluso yo creo que el gallo que es como más ignorante puede llegar a tener una concentración mejor que ninguno de los demás.. yo los observaba..."

(Marcelo Gonzales, ex chino del Baile de Maitencillo).

Esta sensación es descrita como

"...una sensación extraña, yo una vez me disolví en la música, o sea, era como que yo era la música, nada más importaba..."

"con el sonío...te dentra una...sobre too...cuando baila, como que está drogao, así, yo bailaba cuando era chico...ahora me doy cuenta 
que solo de hechar viento...justamente con esta misma religión y too, te dan má gana de bailar, y danzar más. O sea que lo mismo, como volao así, fumao marihuana y too, esto le da así como, como se emborracha así, y siguen bailando..."

“...se siente una emoción grande, o sea, uno empieza a chinear y se emborracha pero se quita cuando empieza a saltar y después da como una emoción y lo único que uno quiere es seguir tocando y saltando..."

(conversaciones con chinos de el baile de El Venado y de Maitencillo).

“...como que no puede soltarla uno (la flauta), una flautea, flautea, flautea y mientras más baila más ganas le dan por flautear...".

(Guillermo Zamorano, chino del Baile de Quebrada Alvarado).

Evidentemente ocurre algo especial en los chinos, algo que los toca profundamente y que los comunica directamente con lo desconocido, se produce un cambio en la percepción, en la relación con el universo, se accede a un plano tan especial que todo el esfuerzo realizado se ve recompensado por ese sentimiento gigantesco, por esa emoción que los lleva a chinear cada vez que se pueda.

"le pesca una corriente, seguir bailando, seguir más bailando, pasa algo...y emoción, se emociona total..ojalá no se terminara nunca esta cuestión así, o sea cuando uno está bailando ojalá siguiera, algo, no sé que pueda ser ah, que lo pesca a uno,

será un espíritu, no sé, algo puede ser, pero algo que lo pesca pero casi no tiene explicación..."

(José Ponce, chino del baile de Quebrada Alvarado).

Nota de campo:

bajar el cerro en procesión en medio del gran tumulto que producen todos los bailes tocando al mismo tiempo y al llegar al patio de la iglesia tocar y tocar tan intensamente y se produce algo tan especial y todo el baile se conecta y tocamos tan bien, acelerando y ralentando tan parejos, inmenso océano de labios y sueños que hace temblar el suelo y el cielo se va quebrando y aparecen ángeles de las grietas y la corriente comienza a inundarme nuevamente mientras tocamos y bailamos a un ritmo frenético y la simetría del sonido es perfecta y ya toco a tres metros del suelo y somos una inmensa flauta dividida en 20 y la felicidad es completa y la emoción y el sentimiento que chorrea en mis pupilas hace huecos en la vida y nos miramos y todos 
sabemos que ahora sí, que el asunto se armó de veras, que todo es perfecto y que las puertas se han abierto. el sonido, ese sonidolleno que cae y sube desde el aire y hacia el aire y estamos en la puerta de la iglesia mientras el baile de Las Palmas está adentro tocando y vamos entrando, traspasando el umbral de la iglesia tocando tan fuerte y Las Palmas adentro tocando frente al altar y ahora sí el sonido es celestial, ambos bailes sonando con toda el alma adentro de la iglesia, cada uno a su ritmo, creando un sonido indescriptible, me despego completamente del suelo y floto en este flujo alucinante de sonidos que entrechocan y se expanden y se arriman y vuelven y somos unas 40 flautas sonando al mismo tiempo y dos bombos y dos tambores y el niño dios que nos mira sonriente, tan sobre nosotros, tan dentro de nosotros, el sonido es un gran abismo que se curva desde nuestros labios hacia el cielo, tocamos y tocamos y la corriente es feroz en mi cuerpo pero da lo mismo, es sólo un asunto más dentro de este gran oceáno en que me muevo y me hundo y salto y me cuelgo del techo y me suelto para seguir flotando, para seguir volando en este sonido alucinante, en este momento único en que estoy tocando en un baile chino dentro de una iglesia y al lado otro baile y el sonido de ambos bailes rebotando por todos los rincones de este mundo y mientras estoy en este estado una señora comienza a entrar a la iglesia arrodillada, descalza, avanzando lentamente hacia el altar, pasando por entre las filas de chinos y yo toco con el corazón al borde de los ojos y ella pasa al frente mio, entre las filas de chinos y sigue su camino hacia el niño dios y toco más fuerte aún porque su gesto me llega tan adentro y todo da vueltas y gira interminablemente y ella llegando al niño dios y rezando con ese fervor que agranda las velas y las lanza sobre todos nosotros y luego ya es parar y comenzar a cantar nuevamente, comenzar la despedida y cantar con don loncho, nuestro alferez.

(fiesta del Niño Dios de Las Palmas de Alvarado, Diciembre 1992)

"siente una cuestión rara, así como que lo sube y lo baja a uno, como que lo levanta y después lo suelta, como que flotara...".

(Polo, chino del baile de Quebrada Alvarado).

Nota de campo:

y entramos a la iglesia y ese cambio incréble de sonido mientras atraviesas la puerta y tocas con los ojos con los dientes con las pestañas y te acercas al niño dios que hoy está de cumpleaños y te mira desde su vestido blanco y la virgen me guiña un ojo y me dice dale no más, no te 
preocupes, y yo bailo y sudo y toco con una alegría inmensa, siendo un pedazo del sonido que cubre toda la iglesia, un pedazo de esta flauta que se inclina y salta para que los ángeles sueñen y se sienten en el gorro del alférez que ha comenzado a cantar y ahi nosotros haciendo ese coro tan sentido, tan desde adentro, subiendo por el altar y entrando a los oídos del niño dios; el techo de la iglesia se curva y se abre sobre mí, el suelo se inclina, las paredes respiran, se agrandan se alejan se acercan en cada soplo; de mi flauta nacen flores, luces, libros, vírgenes, ángeles, cristos sin heridas, cruces sin sangre que pasan volando hacia el altar y se instalan a escucharnos, a mirarnos sonrientes mientras subimos y bajamos y nos retiramos lentamente de la iglesia, siempre mirando hacia el altar, retrocediendo hasta salir y llegar a la noche y a las fogatas que pueblan la noche.

Por mi mente pasan horas, vidas, momentos, años, pasan vivos y muertos, claros y oscuros, círculos y triángulos, por mi mente desfila el universo entero mientras toco y toco esta flauta y el sonido es una gran red, una gigantesca tela de araña que sacude al mundo y todo es gozar de este increíble esfuerzo, de este tocar y cantar sin medida, de este sonido que me toma y me envuelve mostrándome el otro lado del mundo; "gracias a dios que llegué, donde queria llegar, a este pues santo monte, ay, lo vengo a celebrar", y nosotros atrás repitiendo los dos últimos versos en un canto en que dejo todo lo que soy, todo lo que podría haber en mí.

(Fiesta del Niño Dios de Las Palmas de Alvarado, diciembre de 1992).

El baile chino es una manifestación ritual que, debido a sus características, provoca en algunos de los participantes una carga emocional fuertísima produciendo una sensación que se vive sólo en estas ocasiones, una ruptura absoluta con la vida cotidiana, una entrada a un tiempo y a un espacio en que todo cobra otro significado

“justamente yo venía conversando en la mañana con el alférez, que a uno le da una emoción y uno no puede dejar de tocar... porque es algo que uno siente muy adentro, si esto no lo hace uno así pa que lo miren a uno sino que sale de adentro"

(tamborero del baile de Ventana).

Durante el canto a la imagen, el alférez vive momentos muy intensos de comunicación con la divinidad, está cantando la historia sagrada y lo hace desde muy adentro, produciéndose a veces, en algunos alféreces, una gran 
emoción y una vivencia de contacto real con el plano divino, como lo explica Luis Galdames, alférez del baile chino de Ventana:

"yo estaba cantando para San Pedro este año en Horcones y me puse a llorar mientras cantaba y no me importaba, no me daba verguenza ni nada porque lloraba de felicidad mientras cantaba, porque estaba cantando a San Pedro una historia que no está en la Biblia, que está en otro libro, y era como que llegó un espíritu, no sé, algo así y era como si yo estuviera ahí en la historia, como si yo estuviera viviendo realmente la historia, como si estuviera ahí, era tan raro, como si estuviera pasando la historia que yo estaba cantando".

La relación que se produce entonces entre algunos participantes del ritual y el plano divino escapa de la relación cotidiana entre el creyente y la divinidad, se traspasa el umbral de la "realidad cotidiana" para entrar a un plano en que se vive un contacto directo y real con el plano divino.

Nota de campo:

floto en el sonido, en miles de capas de luces paralelas y horizontales que se desplazan a velocidades inimaginables dentro de mi y detrás de mis ojos cerrados, miles de capas de colores se superponen mientras escucho las miles de capas de sonidos que también se superponen y voy flotando en este inmenso océano, esa exquisita sensación de ser parte del universo, ese estado increíble alcanzado con el sonido de las flautas de chino, inmenso puente al otro mundo.

$Y$ esto ya no tiene nada que ver con la hiperventilación, o sea, tiene mucho que ver pero no es lo que ella produce directamente a lo que me refiero, la hiperventilación produce inmediatamente un estado de mareo general, miles de agujas van pinchando sutilmente el cuerpo mientras vas cayendo mentalmente, sientes físicamente una sensación de vahído que puede llegar a ser desagradable pero luego de un rato tocando todo eso desaparece, uno siente intuitivamente la necesidad de comenzar a moverse, comenzar a danzar y ahí ya se va acabando todo el emborrachamiento y se pasa a otro estado, la sensación física desaparece y ahi entonces, cuando las flautas están sonando perfectas, cuando la cantidad de armónicos que sale de cada flauta es la adecuada, cuando son bien tocadas y seguramente son los pares adecuados, se produce esa gigantesca ola de sonidos, el universo entero suspendido en capas de sonidos, es ahí cuando la conciencia salta y abre la famosa puerta y ya dejas el nivel cotidiano, esa felicidad inmensa, esa locura inmensa de tocar, de ser el sonido, de estar en el sonido, de flotar en el sonido y ya dejar de ser hombre, envuelto completamente en esa 
gigantesca corriente de sonido y luces multicolores que se desplazan paralelas, capas de sonidos, capas de luces de colores viajando por el universo en el momento en que tomas conciencia de dónde te encuentras, qué eres, qué haces, sonido y luz, ya ido de lo cotidiano, abandonado al juego de ser un pedazo de tierra un pedazo de árbol un pedazo de todo, todo y nada fundidos absolutamente en uno, el estado mágico de comunicación con el todo, el estado en que todos los dioses de todas las religiones de todos los pueblos de todas las diferentes maneras de explicarse el universo descienden y los miras de frente y eres uno más, porque en ese estado eres todo y no hay yo ni tú ni aquél, todos lo mismo, infinito fluir del universo...

(Fiesta de la Cruz de Mayo de Cai Cai, mayo de 1993).

"...a mí me gusta porque al bailar se emborracha un poco, como que lo toma una corriente a uno, ganas de seguir bailando más, más, más... es como una emoción que da así... seguir bailando, lo pesca algo como... puede ser espíritu, alguna cuestión como que lo atrae a uno,... aparte del emborrachamiento, que bailando se emborracha y bailando se pasa y se mete más en lo que es el canto del alférez también, y el sonido de las flautas, todo eso, que bueno, para mí es bonito, a mí me encanta...".

(José Ponce, chino del baile de Quebrada Alvarado).

Nota de campo:

... ahora sólo nos queda tocar frente al baile de Pachacamita para que los alféreces se despidan, nos largamos a tocar frente a frente y el sonido es delicioso, los alféreces cantan lo que tienen que decirse, nos saludamos de la mano todos los chinos y todo acaba, Armando se me acerca, me da la mano y un abrazo y me dice te felicito, Claudio, te pasate, yo no cré que ibai a poder hacerlo, te felicito, y yo feliz con mi tenida de chino sabiendo que lo hice, que ya soy chino, otros chinos se me acercan y me felicitan, luego las conversaciones entre ellos; pucha el chino pa gueno que agarramo, puta que sonaba linda su flauta oiga amigo rubio, mire con el chino santiaguino ah. y así felicitaciones van y vienen.

Nos sentamos a comer, deben ser como las diez de la noche y Armando insiste en hacer saludes por el nuevo chino y me invita a bailar para el niño dios de las palmas, el 24 de diciembre en la noche y acepto con todo gusto, acaba de terminar esta fiesta y ya tengo unas ganas locas de tocar y bailar nuevamente, e's algo que tira de las venas, le encuentro tanto sentido a lo que me han dicho algunos chinos antes, que una vez 
que se es chino ya no se puede dejar, que hay una necesidad de salir nuevamente y saltar y darlo todo por una flauta.

Ahora me baja el cansancio, el relajamiento y el sueño pero no siento dolor en ningún músculo, la luna aparece entre las ramas del techo de la ramada, otro vaso de vino cayendo al medio de esta felicidad tan grande que está sentada sobre mí, siento las flautas sonando en mi cerebro, miro a la Javiera y le sonrio con una flauta en cada ojo, con una alegría total sobre el rostro, algo tan raro que me traspasa y me tira, una emoción enorme que me une a Armando y al Lalo y a Alberto y a Carlos y a todos los chinos, a todos los que alguna vez han chineado y saben lo que es y lo que se siente al tocar y saltar durante horas, y con ese puente inmenso en los labios me despido y vuelvo a Santiago, a la rutina diaria, a la vida que sigue imperturbable pero tan distinta ya, tan distinta...

(Fiesta de la Virgen de Cai Cai, noviembre de 1992).

\section{Chinos actuales, ¿CHINOS PASAdOS?}

La actual tradición de chinos tiene, al parecer, una larga historia. En esta parte del trabajo me referiré brevemente a ésta, haciendo referencia a datos muy importantes que ayudan a dilucidar el origen de esta tradición.

Existen evidencias arqueológicas y etnohistóricas que permiten trazar una relación entre la actual música de chinos y las antiguas poblaciones indígenas locales. El registro arqueológico cuenta con flautas asignadas al período Aconcagua, población indígena que habitó en la zona central de Chile entre el 900 y 1400 d C. $^{8}$ Estas flautas son construidas en piedra, tienen la misma forma de tubo interior complejo que las flautas actuales, y el sonido que emiten es igual al sonido "rajado" tan preciado por los actuales chinos. Evidentemente esta relación no es casual, sobre todo tratándose de un sonido tan especial y escaso como el que da este tipo de tubo. Las flautas Aconcagua que se han encontrado son pocas y están fuera de contexto, por lo que no es posible, por el momento, conocer asociaciones que ayudarían a esclarecer su uso en la época prehispánica.

Por otro lado, existen datos etnohistóricos que hablan de fiestas religiosas en la zona central y en el norte chico (Andacollo), describiendo instrumentos muy similares, el mismo tipo de sonido y un estilo similar de danzas a partir de 1580 en adelante ${ }^{9}$. Los datos son escasos pero se han encontrado ciertas

\footnotetext{
${ }^{8}$ Ver Grebe, 1974; Pérez de Arce. 1991.

${ }^{9}$ Ver Actas del Cabildo, 1556; Capitanía General, 1763, Concha, 1871; Domeyko, 1978, Galleguillos, 1896; Graham, 1821; Latcham, 1910; Longeville, 1923; Ovalle, 1888; Real Audiencia, 1780.
} 
asociaciones relevantes como son el uso de flautas del mismo tipo pero construidas con huesos de canilla de cóndor y el uso de lenguas indígenas en el canto del alférez, tanto para Andacollo como para La Ligua.

Es importante mencionar además la similitud de los instrumentos, tanto en su forma, construcción interna del tubo, sonido y manera de tocarlos, con la pifilka mapuche. Es evidente que ambos instrumentos están relacionados y sabemos que el mundo Mapuche tuvo contactos con las poblaciones de la zona central de Chile.

Es posible entonces trazar una continuidad de al menos 600 años, en que hay ciertos elementos fundamentales que se mantienen.Tal vez asistimos hoy a los vestigios de una tradición indígena desarrollada en el centro de Chile, que aunque superficialmente se ve como inexistente, al analizarla en profundidad se hacen evidentes ciertos aspectos fundamentales de ella que han sobrevivido a la fuerte occidentalización sufrida en la zona. Los actuales pobladores no se consideran descendientes de indígenas, dicen que han sido siempre campesinos y no hay una conciencia de que antes hubieran vivido indígenas en el lugar. El mestizaje producido entre indígenas y españoles dio como resultado la dominación de la cultura hispánica pero es en las manifestaciones religiosas, las más profundas, donde se puede observar la supervivencia de tradiciones indígenas.

La música es parte de estas manifestaciones religiosas y al parecer hay ciertos elementos indígenas que han permanecido; la forma interior de los instrumentos no cambia, el sonido de los instrumentos no cambia, la estética musical no cambia, y no cambia porque es tan diferente, porque es tan distinta a la que viene con el español que es imposible que se mezclen, hubo entonces dos opciones, o desaparecía completamente o permanecía sin cambios, porque ¿cómo introducir un instrumento o una melodía occidental en esa inmensa orquesta que no tenía nada en común con una orquesta occidental? ¿cómo intentar que esos instrumentos dieran melodías o algo que sonara al menos semejante a la idea de música que traían los españoles?

Se transformaron ciertos aspectos formales del ritual pero hubo otros que no pudieron cambiar; las flautas, el tipo de música, la estética de la música, tal vez porque si cambiaba eso se perdía una parte fundamental del ritual, una parte que era central en el ritual y que era el permitir el acceso a la comunicación directa con los dioses, porque si todas los aspectos que he descrito en este trabajo se conjugan para conformar un ritual estructurado de tal manera que permite inducir un cambio en el estado de conciencia, lógicamente algunos de ellos no podían cambiar sin eliminar ese efecto; la música, ese inmenso espacio sonoro, el esfuerzo físico, la hiperventilación, las horas tocando, todo eso no podía cambiar, pero sí los dioses y el idioma en que el alférez canta, porque en el fondo da lo mismo porque el sentimiento es el mismo, se cambia el nombre de los dioses pero su esencia es la misma; se sigue pidiendo protección divina, se sigue rogando a los dioses aunque ahora se les nombre de otra manera. 
Pareciera que hay ciertos aspectos que pueden cambiar sin transformar la sustancia del ritual, aspectos que aún siendo muy importantes pueden ser reemplazados por otros similares, que significan lo mismo. Allí es donde entraron las nuevas ideas, conceptos y formas que dieron una apariencia hispánica al ritual, enmarcándolo dentro de la religión católica, obligándolo a seguir el discurso oficial, a honrar a sus dioses, a sus santos, a sus templos, pero que no logró, a fin de cuentas, acabar con ese sentimiento profundo de comunicación directa con la divinidad.

Un dato muy interesante aparece en Latcham 1910, refiriéndose a los bailes chinos de Andacollo dice que éstos constituían sociedades secretas. Las sociedades secretas fueron muy comunes en los grupos indígenas americanos y en ellas se mantenían tradiciones y conocimientos fundamentales. Se caracterizaban por ser sociedades cerradas, a las que se entraba luego de una ceremonia de iniciación en la que le eran revelados los conocimientos del grupo, y en la cual el nuevo integrante se comprometía a no revelar sus secretos. Efectivamente Latcham sólo pudo llegar a saber que estas sociedades existían entre los chinos que acudían a Andacollo a comienzos de siglo, pero no le fue permitido conocer sus secretos.

Actualmente en la zona central de Chile, y hasta donde ha alcanzado este estudio, no hay rastros de que esto ocurra, no hay reuniones en que se converse sobre el significado del ritual, no hay especialistas que se dediquen a enseñar los significados de cada uno de los momentos que ocurren en el ritual, no hay personas que enseñen el significado de lo que le ocurre al chino mientras baila, y al ser una experiencia tan difícilmente explicable y comunicable se va encerrando en lo más profundo y personal de cada chino, tal vez ya para siempre.

\section{CONSIDERACIONES FINALES}

¿qué diría este escrito si yo no bailara chino, si yo sólo hubiera mirado y escuchado las fiestas durante dos años?

Hay muchos puntos que quedan por aclarar pero hay sobre todo uno que me parece fundamental y que es hacia donde están dirigidos los próximos pasos de esta investigación. Sabemos que en algunos chinos o alféreces se produce un cambio en el estado de conciencia, sabemos que el chino está inmerso en una fuerte emoción que lo hace vivir una experiencia totalmente no cotidiana, pero el asunto es ahora indagar en el significado que ellos dan a esa experiencia, en la interpretación que ellos hacen de lo que ocurre mientras se chinea en una fiesta.

Al no existir - aparentemente - un corpus teórico que enmarque esta experiencia es muy difícil saberlo, pero es justamente la posible existencia de este corpus la motivación principal de la investigación futura. El que hasta este 
momento, después de dos años de compartir con los chinos, no tenga conocimiento de ese corpus teórico no significa que éste no exista; dos años es muy poco tiempo para enterarse de los niveles más profundos de conceptualización del mundo, sobre todo tomando en cuenta que las experiencias de comunicación directa con la divinidad, de trance o de estados especiales de conciencia, ocurridas fuera de los parámetros establecidos por la doctrina católica han sido considerados tradicionalmente peligrosos y demoníacos por el poder central, y han sido combatidas enérgicamente.

Entonces es bastante probable que ellos se guarden mucho de hablar de estos temas ante una persona que, aunque teniendo una muy buena relación con ellos, viene del "mundo oficial", representa a los "otros" y puede tener algún tipo de relación con la iglesia católica, que vería con ojos espantados esta revelación.

Por otro lado, es importante destacar el papel que juega el marco cultural y la presión social que establece cánones de conducta en que ciertas experencias están excluidas. Tal vez si un chino cuenta alguna experiencia mística que le hubiera ocurrido durante el baile corre el riesgo de ser tomado por un loco, pues las experiencias místicas están reservadas a los santos y a los iluminados, ¿cómo hablar de aquello sobre lo que no se puede hablar, cómo traducir en palabras lo incomunicable?

\section{BiBLIOGRAFÍA}

Actas del Cabildo. 2 de Mayo de 1955. Archivo Nacional. Santiago, Chile.

Capitanía General. 1763, Volumen 690.

Concha, Manuel. Crónica de La Serena desde su fundación hasta nuestros días, 1547-1870. La Serena. Imprenta La Reforma, 1871.

Dobkin de Ríos, Marlene; Fred, Katz. "Some relationship between music and hallucinogenic ritual: the "jungle gym" in conciousness". Ethos, Vol. 3, $\mathrm{N}^{\circ}$ 1. University of California Press. 1975.

Domeyko, Ignacio. Mis Viajes. Ediciones Chile. Santiago, 1978.

Eliade, Mircea. El chamanismo y las técnicas arcaicas del éxtasis. Fondo de Cultura Económica de México, 1960.

Graham, María. Diario de mi residencia en Chile. Santiago. Editorial del Pacífico, 1821.

Grebe, María Ester. "Instrumentos musicales precolombinos de Chile". Revista Musical Chilena, año XXXVIII $N^{\circ} 128,1974$.

Grof, Stanislas. The adventure of self-discovery. State University of New York, 1988.

Halifax, Joan. Shamanic voices. Penguin books. U.S.A., 1979.

Harner, Michael. Alucinógenos y chamanismo. Madrid, Editorial Labor, 1976.

Huguenard, P.; Jaquenoud, J. Anestesiología fundamental. Barcelona. Toray-Masson, S.A., 1967.

Kartomi, Margaret. "Music and trance in Central Java". Ethnomusicology 17. pp. 163-208, 1973.

Latcham, Ricardo. "Virgen de Andacollo, la Fiesta de Andacollo y sus danzas". Anales de la Universidad de Chile, Tomo CXXVI. Enero-Junio 1910.

Lenz, Rodolfo. Diccionurio etimológico. Santiago. Universidad de Chile, 1905-1910. 
Longeville, Ricardo. Memoria de un oficial de marina Inglés al servicio de Chile. Viajes relativos a Chile. Tomo II. Santiago. Fondo histórico y bibliográfico José Toribio Medina, 1962.

Marsh, Caryl. "A framework for describing subjetive states of conciousness". Alternate states of conciousness. New York. The Free Press, 1977.

Martí, Samuel. Canto, danza y música precortesianos. México DF. Fondo de Cultura Económica, 1961.

Neher, Andrew. "A physiological explanation of unusual behavior in ceremonies envolving drums". Human biology 4, pp. 151-160, 1962.

Ovalle de, Alonso. Histórica relación del reino de Chile. Santiago. Instituto de Literatura Chilena, 1996 (1646).

Pérez de Arce, José. "Organología prehispánica de Chile". Culturas prehispánicas de Chile, Vol. 2. Editorial Andrés Bello, 1991.

Real Audiencia. Volumen 2106. 1780.

Rouget, Gilbert. La musique et la transe. France. Editions Gallimard, 1980.

Shultes, Evans; Hoffman, Albert. Las plantas de los dioses. Fondo de Cultura Económica de México DF., 1982.

Stevenson, Robert. Music in Inca and Aztec territory. U.S.A. University of California Press, 1968.

Whitten, Norman. Soul vine shaman. Sacha Runa research foundation, 1979.

Zinberg, Norman. "The study of conciousness states: problems and progress". Alternate states of conciousness. New York. The Free Press, 1977. 